\title{
Attachment dimensions and young children's response to pain
}

\author{
Trudi M Walsh $\mathrm{PhD}^{1}$, Patrick J McGrath $\mathrm{PhD}^{1}$, Douglas K Symons PhD ${ }^{2}$
}

TM Walsh, PJ McGrath, DK Symons. Attachment dimensions and young children's response to pain. Pain Res Manage 2008;13(1):33-40.

BACKGROUND/OBJECTIVE: The present study examined the relationship between attachment dimensions and child pain behaviour following both an everyday pain incident (eg, bumps and scrapes) and acute pain incident (eg, immunization) in 66 five-yearold children.

METHODS: Secure, avoidant, ambivalent and controlling attachment dimensions were assessed using aggregates of laboratory-based reunion behaviour, performance on representational measures of attachment and the measure of emotion regulation. Child pain behaviour, during immunization and everyday pain incidents, was rated in terms of reactivity, anger and calming time.

RESULTS: The ambivalence and controlling attachment dimensions were differentially related to child pain behaviour. Specifically, children with either more ambivalent or controlling attachment had a relatively greater reaction to both the immunization procedure and everyday pain incident. Children with more controlling attachment also took more time to calm down following the immunization and displayed greater anger. Security and avoidance, however, were not systematically related to child pain behaviour.

CONCLUSIONS: Results are discussed in terms of Bowlby's theory of attachment relationships and pain as an important distress signal to children.

Key Words: Attachment immunization; Internal working models; Pain

Dain is a complex, individualized and subjective phenomenon that serves as a signal of threat. While there is clearly a physiological substrate to pain, there is increasing awareness that emotional, experiential and situational factors are important to understanding individual responses to pain. Young children learn to react to internal and external threats that they commonly experience in their social environments (eg, in daycare settings) $(1,2)$. Parents or other caregivers frequently interact with young children who are experiencing stress and pain, and provide an important source of comfort and learning about managing pain. The relatively high occurrence of painful incidents provides the child with a large number of opportunities for learning about pain within a social context (1). The present study examines how the nature of the relationship a young child has with their parent affects their pain behaviour.

Parent-child relationships have been examined within Bowlby's attachment theory (3). Bowlby's view was that

\section{Dimensions de l'attachement et réactions des jeunes enfants à la douleur}

CONTEXTE ET BUT : La présente étude visait à examiner le lien entre les dimensions de l'attachement et le comportement des enfants devant la douleur au cours d'événements douloureux courants (coups, égratignures, etc.) ou d'événements douloureux aigus (immunisation, etc.) chez 66 enfants âgés de 5 ans.

MÉTHODE : Différentes dimensions de l'attachement, soit la sécurité, l'évitement, l'ambivalence et la domination, ont été évaluées à partir d'agrégats du comportement de réunion observé en laboratoire, de la performance sur des mesures représentationnelles de l'attachement et de la mesure de la régulation des émotions. Le comportement des enfants devant la douleur au cours de l'immunisation ou d'événements douloureux courants a été évalué sous les angles de la réaction, de la colère et du temps nécessaire à l'apaisement.

RÉSULTATS : L'ambivalence et la domination étaient liées de manière différente au comportement des enfants devant la douleur. Plus précisément, les enfants ayant un attachement ambivalent ou dominant avaient une réaction relativement plus forte que les autres enfants à l'immunisation ou aux événements douloureux courants. En outre, les enfants ayant un attachement plutôt dominant prenaient plus de temps pour se calmer après l'immunisation et manifestaient plus d'agressivité. Le sentiment de sécurité et l'évitement, par contre, n'étaient pas systématiquement liés au comportement des enfants devant la douleur.

CONCLUSION : Les résultats sont interprétés, d'après la théorie de Bowlby sur les liens de l'attachement et la douleur, comme un important signal de détresse pour les enfants.

${ }^{1}$ Dalhousie University, Halifax; ${ }^{2}$ Acadia University, Wolfville, Nova Scotia

Correspondence: Dr Trudi Walsh, IWK Health Centre, Community Mental Health Service, 40 Freer Lane, Lower Sackville,

Nova Scotia B4C 0A2. Telephone 902-869-5388, fax 902-865-8966, e-mail trudi.walsh@iwk.nshealth.ca 
under-regulation of expressive behaviour displayed by both children with ambivalent or disorganized/controlling attachment reflect problems in emotion regulation (9-13).

Pain is a salient threat that can precipitate a sequence of attachment behaviours (3). It serves as a signal that some harm is occurring and is essential to the body's defence against immediate, as well as future, tissue damage (14). The individual differences observed in children's understanding and response to pain may, in fact, be related to individual differences in attachment security and the internal working models that underlie their attachment. Specifically, in the context of pain, a securely attached child should be able to express his or her needs and appraise the threat realistically. Moreover, given that the experience of security distress is associated with expectations of amelioration (15), the experience of pain for the secure child may become less threatening, and over time the child may develop a better ability to cope with pain situations. A child with a secure attachment has an internal working model in which the attachment figure is seen as a source of comfort and reassurance (16); the child should have little hesitation in seeking comfort or assistance from the attachment figure in more painful situations. That is, a caregiver should be able to serve as a secure base in these cases and, thus, serve as someone to turn to for assistance with pain coping and distress resolution.

A child with an avoidant attachment has an internal working model in which the attachment figure is seen as cold or rejecting (16). Thus, in the context of pain, an avoidantly attached child should not be likely to seek out comfort or assistance from the attachment figure and would actively avoid the caregiver (eg, claim self-reliance in pain situations) or cope on their own. It is unlikely that this child would turn to the caregiver for distress resolution. Moreover, due to the child's previous experience with repeated rejected security-seeking behaviours, the avoidantly attached child is also likely to dismiss the physical symptoms associated with pain and may actually minimize the meaning and expression of his or her pain (8).

Children with an anxious or ambivalent attachment have an internal working model in which the attachment figure is seen as inconsistent or insensitive (16). They are characteristically hypersensitive to negative affect, and show heightened expressions of distress and anger (8). Thus, in the context of pain, a child with an ambivalent or anxious attachment is likely to exhibit excessive expressions of distress (eg, crying, wailing, screaming) to get a response from the caregiver. Once a response is achieved, the child is likely to oscillate between seeking proximity and contact with the caregiver (eg, clinging) and resisting contact and interaction with the caregiver. Moreover, as the child has not developed a sense of autonomy and self-confidence (15), the experience of pain may be viewed as more threatening to the child. Thus, the child is likely to seek assistance from the caregiver in response to painful situations but his or her distress should not be resolved as effectively as that of securely attached children.

A child with a disorganized or controlling attachment has an internal working model in which the attachment figure is seen as frightening (17). As a result, a child with a disorganized or controlling attachment style is likely to appraise pain situations to be more threatening than they really are. However, as approach to the attachment figure is also seen as threatening (17), the child is likely to delay or avoid seeking comfort and may display disorganized behaviour and thought in response to painful situations. What marks this category is an inconsistency of behavioural strategy across situations. Finally, their distress should not be resolved as effectively as that of securely attached children.

While pain has been included as one of several elicitors of attachment in childhood attachment studies, the responses have usually been summed across pain and other contexts (18), with separation from parents being the dominant context. This limits the conclusions that can be drawn about the potential links between attachment and pain behaviour specifically.

In adult pain literature, investigators interested in the individual differences in coping and adjustment to chronic pain have begun to theorize about the relations between attachment and pain behaviour (14,19-23). In addition, adult studies have shown that attachment pattern is related to the duration of physical pain (24) and to the appraisal of - and coping with physical pain (22). These studies, however, provide no information about childhood pain or potential developmental links between relationship processes and pain behaviour.

In an earlier study we examined how imagined pain can elicit attachment behaviour in children (25). In this study, the continuity of preschoolers' internal working models of attachment relationships displayed during separation experience were compared to those displayed during pain experience. The representations of separation and pain experience were systematically related. For example, children who expressed vulnerability about the severe separations also tended to express vulnerability or need about the severe pain situations. In this study, however, pain behaviour was based on the children's self-report for hypothetical pain scenarios. No studies to date have examined observed, rather than imaginary, pain. Internal working models of pain remain to be tested as predictors of actual pain behaviour.

Therefore, the objective of the present study was to assess whether five-year-old children's attachment security and associated working models of relationships would be systematically related to their responses to pain. Children's attachment relationships were assessed using an aggregation of self-report and observational measures of secure base behaviour with parents. Children's response to either everyday pain incidents such as bumps and scrapes, or an acute pain incident such as immunization was assessed using self- and observer-report measures. It was predicted that children with secure attachment should use trusted adults to self-soothe and cope with painful incidents in response to this threat. Alternatively, children with insecure attachment (eg, controlling, ambivalent and avoidant) should be less able to control their reaction because of their inability to use adult comfort.

\section{Participants}

\section{METHOD}

The participants were 66 children, mean $( \pm S D)$ age $5.07 \pm 0.35$ years, recruited from local medical clinics, and their biological mothers (mean age $36.64 \pm 4.42$ years). Participants spoke English as a first language and were primarily of European-Canadian descent (90.9\%). Of the children, $30(45.5 \%)$ were female, 63 (95.4\%) came from two-parent households and 12 (18.2\%) had no siblings. Family socioeconomic status (SES), calculated using the Hollingshead twofactor index of social position (26), showed that the majority 
of participants had mid to high SES. The participants recruited from the four medical clinics did not differ on demographic variables.

\section{Measures}

Attachment-relevant constructs: Consistent with the suggestion of Main and Cassidy (27), children's attachment was assessed using both representational and behavioural measures. In addition, given the proposed link between attachment and the regulation of emotion (5-8), a measure of emotion regulation was also included.

Representational measures: Two representational measures were used: the Separation Anxiety Test (SAT) $(28,29)$, which assesses children's responses to representations of separations from parents; and the Pain and Relationship Task (PART) (25), which assesses children's responses to representations of anticipatory pain situations. The stimuli for the SAT included six black and white photographs depicting separation situations, three of which are considered severe (eg, parents are going away for two weeks) and three of which are considered mild (eg, mother tucks child in bed and leaves the room). The stimuli for the PART included six black and white, ink drawn, Charleston Pediatric Pain Pictures (30) depicting three severe (eg, child burning hand on stove) and three mild (eg, having a book fall on foot) pain situations. Copies of the parent pictures from the Family Relations Test - Children's Version (31) were modified to include neutral facial expressions, reflect cultural diversity and accompany the presentation of the pain pictures. The parent pictures were available to be integrated, or not, into the child's response at the child's discretion.

With these tasks, participants were shown each picture followed by a brief description of the situation, then asked how the depicted child might feel, why the child feels that way and what the child might do. In accordance with Slough and Greenberg (29), the participants were first asked a set of questions about the child in the picture, followed by questions about how the participants themselves felt. Sex-matched pictures were used.

The participants' videotaped responses to each question were transcribed verbatim for scoring. The scoring system for the SAT was based on Slough et al (32), and involved assigning SAT responses to one of 21 categories, and PART to one of 19 categories. For both the SAT and PART, the categories yielded three subscale scores: attachment security (feelings of vulnerability about the separations or pain situations); selfreliance (self-confident about handling the separations or pain situations more or less independently); and avoidance (avoidance of the discussion of the separations or pain situations). The ratings were given twice, once for the hypothetical child in the picture and once for how the participant would feel.

To establish the reliability of the coding schemes, blinded raters rescored 20\% of the SAT and PART transcripts. For both the self- and other-reference data, the inter-rater reliabilities were established at an acceptable level for the allocation of individual responses to the subcategories on which the final scoring was based (Kappa greater than 0.80; range 0.81 to 0.86 ). In addition, the subscale scores were reliable, with $r$ greater than 0.90 between like variables. The primary rater's responses were used in the analyses.

Behavioural measure of attachment: A separation-reunion procedure was used to provide a behavioural measure of attachment (27). With this procedure, parents and children were separated for approximately $1 \mathrm{~h}$ during which the individual testing procedures were carried out (eg, administration of the SAT). At the end of the separation, the mother and child were allowed to reunite for $2 \mathrm{~min}$.

The reunion was videotaped and later coded using the Parent/Child Reunion Inventory (P/CRI) (33). The P/CRI is based on research by Main and Cassidy (27) and the theoretical constructs of Ainsworth et al (16). The inventory consists of 20 behavioural items, originally described in Main and Cassidy (27), which can be rated by either the parent or an observer. The rater is asked to rate the typical occurrence of each behavioural item as $0=$ never, $1=$ occasionally and 2 = usually, following a separation and reunion. Six of the reunion items pertain to secure behaviours (eg, child initiates positive interaction with the parent) and can be summed to provide an overall subscale score of secure behaviour with a possible range of scores from 0 to 12 , with higher scores reflecting greater security. The remaining 14 items pertain to insecure behaviours (eg, child stays away from the parent) and can be summed to provide an overall subscale score of insecure behaviour with a possible range of scores from 0 to 28 , with higher scores reflecting greater insecurity. The insecure items can also be subdivided to reflect Main and Cassidy's avoidant, ambivalent and controlling attachment classifications (18).

In the present study, coders (blind to the children's other scores) reviewed the videotaped reunions and scored the interactions between the mother and child on the behavioural items. The item scores were then summed in accordance with Marcus $(33,34)$ and averaged to create four rating scales: secure, avoidant, ambivalent and controlling behaviour. The primary coder, blind to all other information about the children including the SAT and PART scores, coded the reunions. Twenty per cent (13) of test tapes were randomly selected and coded by a second coder for inter-rater reliability. The Kendall's tau b correlations for these cases were as follows: 0.91 on the secure behaviour rating scale; 0.88 on the avoidant behaviour rating scale; 0.80 on the ambivalent behaviour rating scale; and 0.99 on the controlling behaviour rating scale. The overall kappa for the individual coding judgments were 0.88 .

Emotion regulation: The Emotion Regulation Checklist (ERC) (35) is a 24-item, other-report measure of children's self-regulation and targets processes central to emotion regulation such as affective lability, intensity, valence, flexibility and situational appropriateness. With this measure, raters familiar with the child are asked to judge how characteristic each item is for the child on a four-point Likert scale ranging from 1 (almost always) to 4 (never). Two subscale scores are then derived from the ratings. The lability/negativity subscale is composed of items pertaining to mood swings, angry reactivity, emotional intensity and dysregulated positive emotions. Scores on this subscale have a possible range of 15 to 60 with higher scores reflecting greater dysregulation. The emotion regulation subscale contains items reflecting processes central to adaptive regulation including equanimity, emotion understanding and empathy. Scores on this subscale have a possible range of 8 to 32 , with higher scores reflecting greater regulation. In the present study, mothers completed the ERC.

\section{Aggregation of attachment relevant constructs}

Several measures were used to assess the construct of attachment in the present study. It has been suggested that the sum of a set of multiple measurements is a more stable and representative 
estimator of a construct than any single measurement (36). By combining numerous exemplars, particularly those using different measurement procedures or domains, the idiosyncratic variance associated with measurement is averaged out (36).

To increase the psychometric precision of the attachment constructs and to reduce the number of predictor variables used in the analyses, an aggregation procedure was employed to create overall dimension scores of security, avoidance, ambivalence and control. With this procedure, correlations between theoretically related attachment constructs were first examined to determine if the separate measures were indeed related. The individual scale scores were then converted to z-scores and averaged to create an aggregate dimension score. Scores were weighted so that representational, observational and parent report measures contributed equally to the aggregate. Higher scores on the aggregate dimensions reflect greater attachment security, avoidance, ambivalence or control, as appropriate.

For the security dimension, the z-scores for the SAT and PART attachment rating scale, self-reliance rating scale, selfand other-reference scores, P/CRI secure behaviour rating scale mean scores and ERC emotion regulation subscale scores were combined to produce an aggregate security dimension score (mean score $-0.0088 \pm 0.17$, range -0.47 to 0.29 ; Cronbach's alpha $=0.72$ ). For the avoidance dimension, the normalized $z$-scores for the SAT and PART avoidance rating scale, self- and other-reference transformed scores and P/CRI avoidant behaviour rating scale mean scores were combined to produce an aggregate avoidance dimension score (mean score $-0.014 \pm 0.30$, range -0.42 to 0.70 ; Cronbach's alpha $=0.82$ ). For the controlling dimension, the P/CRI controlling behaviour rating scale mean score and the ERC lability/negativity subscale $z$-scores were averaged to produce a controlling dimension aggregate score (mean score $-0.0053 \pm 0.79$, range -1.14 to 3.15 ; Cronbach's alpha $=0.71$ ). The P/CRI ambivalent rating scale was not significantly correlated with the ERC subscale as predicted; thus, an ambivalence dimension aggregate score could not be calculated. Thus, P/CRI ambivalent behaviour rating scale mean scores were used in the analyses (mean $0.35 \pm 0.49$, range 0 to 2 ). Aggregate and P/CRI ambivalent behaviour rating scale mean scores were transformed as preliminary analyses showed that the distributions were positively skewed. Transformed scores were used in the main analyses.

\section{Measurement of child pain response}

Facial action: Video recordings of child pain behaviour during immunization were coded using the Children's Facial Coding Scale (CFCS) (37). The CFCS is an observational rating system that measures pain-related facial activity by assessing the intensity $(0=$ absent, $1=$ present and slightly obvious, $2=$ present and appears distinctly to maximally and is clearly obvious) of 13 facial actions during a given time period. In the present study, only five facial actions (brow lower, eye squeeze, nose wrinkler, cheek raiser and upper lip raiser) were measured, because these five facial actions are thought to provide the bulk of information about pain (38). The total facial action is then calculated as the sum of intensity and occurrence ratings of all facial actions within a given time period.

A continuous time period was recorded during the immunization and was broken down into three primary intervals: baseline, injection and recovery. The 'baseline' period included the $10 \mathrm{~s}$ immediately before insertion of the first needle, the 'injection' period included the seconds beginning with the insertion of the first needle and continuing to $10 \mathrm{~s}$ following insertion of the second needle, and the 'recovery' period that included the $10 \mathrm{~s}$ immediately following the injection period. For the three children who received only one needle, the injection period was recorded as the $10 \mathrm{~s}$ immediately following insertion of the needle. For the children receiving two needles, the injection period was further broken down into 'needle 1' (10 s immediately following insertion of the first needle) and 'needle 2' (10 s immediately following insertion of the second needle) to control for individual differences due to variable time periods in which the immunizations occurred. Within each interval, $1 \mathrm{~s}$ blocks were coded.

During data coding, $20 \%$ of the tapes were randomly selected and coded by a second blind rater to determine interrater reliability using the formula by Ekman and Friesen (39) $(\%$ agreement $=$ [number of actions with coder agreement $\times 2$ ] $\div$ total number of actions coded). Mean inter-rater reliability across facial actions was 0.86 (range 0.78 to 0.92 ).

Self-reported pain: A Faces Pain Scale (FPS) (40) was used to assess children's self-report of pain during immunization and everyday pain incidents. The FPS is a seven-item scale depicting serially ordered drawn faces of increasing pain intensity. Scores on the FPS range from 0 to 6 , with higher values reflecting greater pain intensity. Following instructions on how to use the scale, the child was asked to circle the face that best described their pain. To establish reliability, an adult observer also rated the child's perceived pain using an FPS immediately following the immunization. Inter-rater reliability between child and observer was $r(64)=0.62, \mathrm{P}<0.001$ using Pearson correlation. Children's self-report FPS scores were used in the analyses.

Reactivity, anger and calming time: The child's reaction to immunization and everyday pain was assessed with motherreported rating scales pertaining to how strongly the child reacted using a $100 \mathrm{~mm}$ visual analogue scale ranging from 'no response' to 'strongest possible response'; how angry the child became using a $100 \mathrm{~mm}$ visual analogue scale ranging from 'no anger' to 'as angry as can be'; and amount of time needed for the child to calm down (in seconds). Following the immunization, an adult observer also completed the rating scales. Interrater reliabilities between mother and observer were as follows: reactivity level $(r[64]=0.69, P<0.001)$, anger level $(r[64]=0.50$, $\mathrm{P}<0.001)$ and calming time $(\mathrm{r}[64]=0.75, \mathrm{P}<0.001)$. Mothers' scores were used in the analyses.

\section{Measurement of covariates}

Three potential covariates were also assessed in the present study. First, as the SAT and the PART rely on the child's ability to formulate and produce coherent verbal responses, receptive language ability was assessed using the Peabody Picture Vocabulary Test - third edition, Form IIIA (PPVT-III, Form IIIA) (41). The PPVT-III is an individually administered, untimed, norm-referenced, wide-range test of verbal ability. An age-appropriate standard score is derived with higher scores reflecting better-developed verbal ability. Second, as performance on both the SAT and PART rely, in part, on the child's ability to identify and label emotional states, emotional awareness was assessed using the Emotional Labelling Task (ELT) (42-44). The ELT determines the child's ability to differentiate emotional states by having the child identify, verbally and by pointing, various facial expressions. The stimuli 
for this task include five colour photographs of a four-year-old child modeling facial expressions of happiness, anger, surprise, sadness and fear. With the ELT, the child is shown each picture and asked to identify the five facial expressions using an openended and closed-ended format. The total ELT score is the sum of correct responses. Finally, given the interactive nature of the reunion procedure, it is possible that situational variables (eg, atypicality of the child's mood or behaviour at the time of the study interview) may influence the child's behaviour with the mother. Thus, a rating scale of child situational variables at the time of testing was included. With this measure, mothers were asked to indicate, using ordinal scales, how well their child slept the previous night, how tired their child was on the day of testing, how good their child's general mood was on the day of testing, and how typical their child's behaviour was on the day of testing.

\section{Procedure}

During the laboratory visit, the children completed the ELT, followed by administration of either the SAT or PART. The children then completed the PPVT-III, followed by administration of either the SAT or PART. Each session was videotaped and the order of administration of the SAT and PART was counterbalanced across participants. In an adjacent room mothers completed a demographic questionnaire, the ERC and were given reactivity, anger, calming time and FPS rating scales to complete at home following four everyday pain incidents. Of the 66 mothers who participated, 25 (37.9\%) returned four completed forms, $15(22.7 \%)$ returned three completed forms, 11 (16.7\%) returned two completed forms, three $(4.5 \%)$ returned one completed form, and $12(18.2 \%)$ did not return any forms. Of the completed forms, a minimum of one of the pain incidents per participant was reported to be somewhat to very typical. Given the variability in the number of pain incident report forms, only one incident per participant was included in the analyses. The incident included was randomly selected from the forms indicated as somewhat or very typical.

After the tasks were completed, the mother and child were allowed to reunite alone for $2 \mathrm{~min}$. The reunion was videotaped and later coded for attachment variables.

During the medical clinic visit, children received a diphtheria, pertussis, tetanus and poliomyelitis vaccine (DaPTP) given intramuscularly; and a live attenuated measles-mumpsrubella vaccine (MMR) given subcutaneously. Three of the participants received only the MMR vaccination. Recordings were made from the time before the child's arm was swabbed until approximately $30 \mathrm{~s}$ after removal of the second needle. Following the immunization, the mother and the researcher rated the child's reactivity, anger and calming time. The child was also asked to complete a FPS about the immunization procedure.

\section{RESULTS}

Before the main analyses, Spearman and Pearson correlations were conducted between the demographic variables (eg, child age, child sex, maternal age, marital status, employment status, educational level, family SES) and the study variables to determine which, if any, demographic variables should be included as covariates in the main analyses. No significant correlations were found. Pearson correlations also showed that the SAT and PART scores were unrelated to the PPVT-III and the ELT
TABLE

\begin{tabular}{llrr}
\multicolumn{4}{l}{ Descriptive statistics for the child pain variables } \\
\hline \multicolumn{1}{l}{ Variable } & Range & Mean & \multicolumn{1}{c}{ SD } \\
\hline CFCS summary scores & & & \\
Baseline & $0-67$ & 15.20 & 15.27 \\
Injection & $0-461$ & 103.68 & 95.53 \\
Needle 1 & $0-63$ & 21.69 & 22.66 \\
Needle 2 & $0-94$ & 23.37 & 20.33 \\
Recovery & $0-81$ & 14.97 & 17.60 \\
Immunization scales & & & \\
Faces Pain Scale & $0-6$ & 2.21 & 2.14 \\
Reactivity level, mm & $0-100$ & 27.89 & 27.41 \\
Anger level, mm & $0-100$ & 8.52 & 20.89 \\
Calming time, s & $0-180$ & 24.05 & 36.46 \\
Everyday pain scales & & & \\
Faces Pain Scale & $0-6$ & 2.85 & 1.76 \\
Reactivity level, mm & $0-86$ & 45.09 & 23.68 \\
Anger level, mm & $0-65$ & 11.08 & 17.55 \\
Calming time, s & $0-150$ & 47.38 & 35.41
\end{tabular}

$n=66$. Raw scores were logarithmically transformed because preliminary analyses showed that the distributions were positively skewed. Transformed scores were used in the main analyses. CFCS Child Facial Coding Scale

total scores, suggesting that neither language ability nor emotional awareness accounted for performance on the representational measures. Finally, correlations showed that the situational variables (eg, how tired the child was on the day of testing) were unrelated to the interactive reunion behaviour rating scales.

To examine the relations between attachment dimensions and child pain behaviour, bivariate correlations were calculated between the aggregate security dimension, aggregate avoidance dimension, ambivalence dimension and aggregate controlling dimension scores, and children's responses to the immunization and everyday pain incident. Descriptive statistics for the child pain behaviour variables are presented in Table 1.

The inter-correlations of the attachment dimensions and child pain variables are presented in Table 2 . The first hypothesis was that the attachment dimensions would be equivalent in terms of baseline levels of pain and self-report of pain experienced before the needle and everyday pain incidents. Consistent with prediction, there were no significant correlations between the attachment dimensions and children's selfreport of pain and facial action during the needle baseline period.

The second hypothesis was that because securely attached children seek comfort or assistance from the mother and are able to be soothed by the mother during the pain incidents, the secure attachment dimension would be negatively related to reactivity level and calming time during the pain incidents. Contrary to this prediction, no significant correlations were observed between the secure attachment dimension and the child pain variables.

The third hypothesis was that children with relatively greater avoidant attachment should minimize expressions of negative affect and pain-related facial activity and should not be able to be soothed by the mother should she initiate assistance during the pain incidents. Specifically, it was predicted that the avoidance attachment dimension would be negatively 
TABLE 2

Correlations between the attachment dimension scores and child pain variables

\begin{tabular}{lcccc}
\hline & \multicolumn{4}{c}{ Attachment dimension } \\
\cline { 2 - 5 } Variable & Security & Avoidance & Ambivalent & Controlling \\
\hline CFCS summary scores & & & & \\
Baseline & 0.07 & -0.11 & 0.15 & 0.08 \\
Injection & 0.06 & -0.09 & $0.28^{*}$ & $0.40^{\star *}$ \\
Needle 1 & -0.08 & -0.04 & $0.26^{*}$ & $0.28^{\star *}$ \\
Needle 2 & -0.02 & -0.12 & 0.19 & $0.38^{\star *}$ \\
Recovery & 0.12 & -0.22 & 0.10 & 0.18 \\
Immunization scales & & & & \\
Faces Pain Scale & -0.02 & 0.05 & 0.20 & 0.19 \\
Reactivity level, mm & -0.02 & -0.04 & 0.01 & $0.38^{\star *}$ \\
Anger level, mm & 0.07 & 0.06 & 0.10 & $0.42^{\star *}$ \\
Calming time, s & 0.09 & -0.08 & -0.05 & $0.29^{*}$ \\
Everyday pain scales & & & & \\
Faces Pain Scale & 0.16 & -0.26 & 0.08 & 0.04 \\
Reactivity level, mm & 0.04 & -0.03 & $0.48^{* * *}$ & $0.38^{* * *}$ \\
Anger level, mm & 0.04 & -0.11 & 0.26 & 0.26 \\
Calming time, s & 0.11 & -0.11 & 0.18 & 0.25 \\
\hline
\end{tabular}

$n=66,{ }^{*} P<0.05,{ }^{* *} P<0.01,{ }^{* * *} P<0.001$. CFCS Child Facial Coding Scale

related to facial action during the injection, needle 1, needle 2 and recovery periods; and negatively related to reactivity level and calming time during the pain incidents. Contrary to prediction, no significant correlations were observed.

The fourth hypothesis was that children with relatively greater ambivalent attachment should express more negative effect and seek comfort or assistance from the mother, but also exhibit resistant and angry behaviour and be less able to be soothed by the mother. Specifically, it was predicted that the ambivalence attachment dimension would be positively related to facial action during the injection, needle 1 , needle 2 , and recovery periods, to reactivity level, anger level and calming time during the pain incidents. Partial support for these predictions was found. Specifically, there were significant positive correlations between the ambivalence dimension and overall injection, and needle 1 CFCS summary score and everyday pain reactivity level. Thus, children with more ambivalent attachment displayed greater facial action during the overall injection and first needle period and had a relatively greater reaction to the everyday pain incident than children with less ambivalent attachment.

The fifth hypothesis was that children with relatively greater disorganized or controlling attachment should express more negative affect, either seek comfort or assistance from the mother or alternatively avoid the mother and be less able to be soothed by the mother. Specifically, it was predicted that the controlling attachment dimension would be positively related to facial action during the injection, needle 1 , needle 2 , and recovery periods, and to reactivity level and calming time during the pain incidents. As predicted, several significant correlations were observed between the controlling dimension and child pain variables. First, the controlling dimension was significantly and positively correlated with overall injection, needle 1, and needle 2 CFCS summary scores. Thus, children with more controlling attachment displayed greater facial action during the injection, needle 1 , and needle 2 periods than children with less controlling attachment. Second, the controlling dimension was significantly and positively correlated with reactivity level and calming time following the immunization. There was also a significant positive correlation between the controlling dimension and immunization anger level. Thus, children with more controlling attachment had a relatively greater reaction to the immunization procedure, displayed greater anger and took more time to calm down. Finally, the controlling dimension was significantly and positively correlated with everyday pain reactivity level, indicating that children with more controlling attachment had a relatively greater reaction to the everyday pain incident.

\section{DISCUSSION}

The primary purpose of the present study was to examine the relations between attachment dimensions and child pain behaviour following both an acute pain incident (eg, immunization) and everyday pain incident (eg, bumps and scrapes) in a sample of 66 five-year-old children and their mothers. Overall, the results of this study showed the ambivalence and controlling attachment were differentially related to child pain behaviour. Specifically, children with either more ambivalent or controlling attachment styles had a relatively greater reaction to both the immunization procedure and everyday pain incident. Children with more controlling attachment also took more time to calm down following the immunization and displayed greater anger. These findings were independent of children's baseline levels of pain and amount of pain experienced during the incidents and suggest that heightened pain reactions and behaviours were not due to the children 'feeling' more pain than the other children and thus reacting stronger.

These results are consistent with Bowlby's (3) account of internal working models. Children with an anxious-ambivalent attachment have an internal working model in which the attachment figure is seen as inconsistent or insensitive (16), and are characteristically hypersensitive to negative affect and show heightened expressions of distress (8). Thus, in the context of pain, a child with an anxious-ambivalent attachment would exhibit excessive expressions of distress (eg, crying, wailing, screaming) to get a response from the caregiver. Similarly, children with a disorganized or controlling attachment have an internal working model in which the attachment figure is seen as frightening (17). As a result, a child with a disorganized or controlling attachment style is likely to appraise pain situations to be more threatening than they really are and, as a result, show a greater negative reaction to pain and have less effective distress resolution.

Security and avoidance, however, were not systematically related to child pain behaviour. However, while these attachment dimensions were not concurrently related to pain behaviour, they may still be longitudinally related. It is also possible that the lack of concurrent effect may be related to the nature of the variables studied (eg, overt versus covert reactions). The attachment system enables a child to use attachment figures as a secure base across time and distance, from which the child feels safe to explore and master the environment when there is no apparent threat. The caregiver serves as a safe haven to which the child can turn for reassurance and comfort in situations where the child perceives a threat in the immediate environment (eg, 'security distress'). Thus, the goal of the attachment system is twofold. From the viewpoint of the observer, the goal is to regulate behaviours designed to establish or maintain contact (eg, crying) with the attachment figure. 
From the viewpoint of the individual, the goal of the attachment system is 'felt security' $(16,45)$.

Felt security as a goal is defined from an organizational perspective and reflects "the entire pattern of the individual's reaction to events in relation to emotional security as a goal, as opposed to simply those reactions that are conscious or reported as feelings" (45), as well as behavioural and physiological reactions. However, children's security behaviours need not necessarily be congruent with their felt security (45). Thus, measuring children's reactions to security distress in terms of observable behaviours only may not completely capture the relations between attachment and the experience of pain.

There are a few limitations that need to be addressed. First, the correlational approach limits firm conclusions that can be made about the directionality of the observed relations. The correlational approach also does not allow for a complete examination of potential third variables (eg, maternal sensitivity) that may account for the observed relations or the lack of predicted relations. Second, the cross-sectional nature of this study does not allow the developmental or causal relations between attachment dimensions and pain response to be addressed. Third, the reliance on only maternal report of everyday pain might be problematic. However, the relatively good reliability found on most of the immunization pain form subscales suggests that the maternal reports of everyday pain provide an accurate account of the pain incidents. In addition, it is possible that recording everyday pain incidents itself have had reactive effects and may have cued the mothers, in particular the mothers of the insecurely attached children, to pay more attention to the pain and thus report greater pain reactivity. Similarly, the use of the everyday pain rating scales may have prompted the mothers to alter their behaviour in response to the child's pain incident. Fourth, only acute pain incidents were examined. While acute pain incidents comprise the majority of pain experience that children are familiar with, it would also be interesting to examine if individual differences in coping and adjustment to chronic pain in children are related to attachment dimensions. Fifth, while a sum of a set of multiple measurements is a more stable and representative estimator of a construct than any single measurement, aggregation procedures do not examine the direct relations between the individual components that comprise the aggregate and the outcome variables. Finally, while the sample was representative of Atlantic Canada, the participants were drawn from a largely white and English-speaking population and were primarily middle and upper-middle class. Thus, the generalizability of the findings to other populations should be made with caution. In addition, the inclusion of only mothers precludes generalizability of the findings to father-child pain interactions, which may be different.

Despite these limitations, these data have implications for both pain research and attachment theory. From a theoretical perspective, the results re-emphasize the complexity of pain and the inherent difficulty in making broad statements about children's pain and the factors that predict it. For instance, given the lack of correspondence between children's responses to different types of pain it would be incorrect to generalize the wealth of knowledge gathered in medical pain situations to more common pain experience in children. Moreover, while support was found for many, but not all of the hypotheses, this study underscores that the factors involved in predicting pain and its behavioural expression are equally complex.
That is to say that attachment clearly is not the only factor involved as the percentage of variance accounted for is small. Continued examination of the individual context in which pain occurs remains important.

The results also suggest that Bowlby's (3) theory of attachment generalizes to a child's internal working model of pain. Separation from parents has dominated research over the past 30 years, in part due to the emphasis of the Strange Situation procedure (16). The present study suggests that secure base phenomena extend to pain situations, which have been given only cursory attention in attachment literature. Just as separation from caregivers can be a threat to survival of the young human child, so too can be the physical damage indicated by perceived pain. Both are emergencies that may elicit secure base behaviour.

The study also serves as a bridge between attachment theory and current theories of children's concept of - and response to pain. Researchers interested in conceptualizing children's differential understanding of - and response to - pain have typically focused on various psychosocial factors, such as temperament $(46,47)$, social modeling (48) and maternal sensitivity (49). The present study, however, is the first to provide evidence, albeit limited, that children's differential response to pain may be a function of their attachment security.

ACKNOWLEDGEMENTS: The authors wish to thank Alyson Currie, Cathy Stewart, Anna Fong, Helen Fong and Stephanie Dort for their assistance with data collection and coding. Special thanks also to Dr Brad Frankland for his statistical advice. The present study would not have been possible without the participation of the children and families, as well as the staff at Dalhousie Health Services, Woodlawn Medical Clinic, Musquodoboit Harbour Medical Clinic, and Sunnyside Mall Medical Clinic in Nova Scotia. This article is based on research collected as part of the first author's dissertation: "Relations between attachment dimensions, internal working models, and young children's response to pain". This research was supported in part by the Social Sciences and Humanities Research Council of Canada. Dr McGrath was supported by a Canada Research Chair.

\section{REFERENCES}

1. Fearon I, McGrath PJ, Achat H. 'Booboos': The study of everyday pain among young children. Pain 1996;68:55-62.

2. von Baeyer CL, Baskerville S, McGrath PJ. Everyday pain in threeto five-year-old children in day care. Pain Res Manag 1998;3:111-6.

3. Bowlby J. Attachment and Loss: Attachment, $2^{\text {nd }}$ edn. New York: Basic, 1982.

4. Bretherton I. Attachment theory: Retrospect and prospect. In: Bretherton I, Waters E, eds. Growing points in attachment theory and research. Monographs of the Society for Research in Child Development 1985:50(Ser No 209):3-36.

5. Bowlby J. Attachment and Loss: Loss, Sadness and Depression. New York: Basic, 1980.

6. de Rosnay M, Harris PL. Individual differences in children's understanding of emotion: The roles of attachment and language. Attach Hum Dev 2002;4:39-54.

7. Main M, Kaplan N, Cassidy J. Security in infancy, childhood and adulthood: A move to the level of representation. In: Bretherton I, Waters E, eds. Growing points of attachment theory and research. Monographs of the Society for Research in Child Development, 1985:50(Ser No 209):66-104.

8. Cassidy J. Emotion regulation: Influences of attachment relationships. In: Fox NA, ed. The Development of Emotion Regulation: Biological and Behavioral Considerations. Monographs of the Society for Research in Child Development 1994:59(Ser No 240):228-49. 
9. Block JH, Block J. The role of ego-control and ego-resiliency in the organization of behavior. In Collins WA, ed. Minnesota Symposia on Child Psychology, Vol 13. Hillsdale: Lawrence Erlbaum, 1980.

10. Cole PM, Michel MK, Teti LO. The development of emotion regulation and dysregulation: A clinical perspective. Monogr Soc Res Child Dev 1994:59:73-100

11. Eisenberg N, Fabes RA, eds. Emotion and its Regulation in Early Development. San Francisco: Jossey-Bass Inc, 1992

12. Fox NA. Psychophysiological correlates of emotional reactivity during the first year of life. Dev Psychol 1989;25:364-72.

13. Green J, Goldwyn R. Annotation: Attachment disorganisation and psychopathology: New findings in attachment research and their potential implications for developmental psychopathology in childhood. J Child Psychol Psychiatry 2002;43:835-46.

14. Mikail SF, Henderson PR, Tasca GA. An interpersonally based model of chronic pain: an application of attachment theory. Clin Psychol Rev 1994;14:1-16

15. Kobak RR, Sceery A. Attachment in late adolescence: Working models, affect regulation and representations of self and others. Child Dev 1988;59:135-46

16. Ainsworth MDS, Blehar MC, Waters E, Wall S. Patterns of Attachment: A Psychological Study of the Strange Situation. Hillsdale: Lawrence Erlbaum, 1979.

17. Main M, Solomon J. Discovery of a new, insecuredisorganized/disoriented attachment pattern. In: Yogman M, Brazelton TB, eds. Affective Development in Infancy. Norwood: Ablex, 1986:95-124.

18. Cicchetti D, Cummings EM, Greenberg MT, Marvin RS. An organizational perspective on attachment beyond infancy: Implications for theory, measurement, and research. In: Greenberg MT, Cicchetti D, Cummings EM. eds. Attachment in the Preschool Years: Theory, Research, and Intervention. Chicago: The University of Chicago Press, 1990:3-49.

19. Anderson DJ, Hines RH. Attachment and pain. In: Grzesiak RC, Ciccone DS, eds. Psychological Vulnerability to Chronic Pain. New York: Springer Publishing Company Inc, 1994:137-52.

20. Hallberg LR, Carlsson SG. Psychosocial vulnerability and maintaining forces related to fibromyalgia. In-depth interviews with twenty-two female patients. Scand J Caring Sci 1998;12:95-103.

21. Kolb LC. Attachment behavior and pain complaints. Psychosomatics 1982;23:413-25.

22. Mikulincer M, Florian V. The relationship between adult attachment styles and cognitive reactions to stressful events. In: Simpson JA, Rholes WS, eds. Attachment Theory and Close Relationships. New York: Guilford Press, 1998:143-65.

23. Porter LS, Davis D, Keefe FJ. Attachment and pain: Recent findings and future directions. Pain 2007;128:195-8.

24. Scott D. An examination of the relationship between duration of physical pain, adult attachment pattern, and current depression. (Doctoral dissertation, California School of Professional Psychology, 1989). Dissertation Abstracts International 1989/1990:50(10-B):4785.

25. Walsh TM, Symons DK, McGrath PJ. Relations between young children's responses to the depiction of separation and pain experiences. Attach Hum Dev 2004;6:53-71.

26. Miller DC. Handbook of Research Design and Social Measurement. New York: Mackay, 1977.

27. Main M, Cassidy J. Categories of response to reunion with the parent at age 6: Predictable from infant attachment classifications and stable over a 1-month period. Dev Psychol 1988;24:415-26.
28. Klagsbun M, Bowlby J. Responses to separation from parents: A clinical test for young children. Br J Projective Psychol Personality Study 1976;21:7-27.

29. Slough NM, Greenberg MT. Five-year-olds' representations of separation from parents: Responses from the perspective of self and other. In: Bretherton I, Watson MW, eds. Children's Perspectives on the Family. New Directions for Child Development. San Francisco: Jossey-Bass, 1990:67-84.

30. Belter RW, McIntosh JA, Finch AJ Jr, Saylor CF. Preschoolers' ability to differentiate levels of pain: Relative efficacy of three selfreport measures. J Clin Child Psychol 1988;17:329-35.

31. Bene E, Anthony J. Family Relations Test - Children's Version. Windsor: The NFER-Nelson Publishing Co. Ltd, 1985.

32. Slough NM, Goyette M, Greenberg MT. Scoring indices for the Seattle version of the separation anxiety test. Washington: University of Washington, 1988.

33. Marcus RF. Parent/Child Reunion Inventory. Maryland: University of Maryland, 1988.

34. Marcus RF. The Parent/Child Reunion Inventory: A measure of attachment beyond the infancy years. Psychol Rep 1990;67:1-2.

35. Shields A, Cicchetti D. The development of an emotion regulation assessment battery: Reliability and validity among at-risk grade school children. Poster session presented at the biennial meeting of the Society for Research in Child Development, Indianapolis, IN, 1995.

36. Carlson SM, Moses LJ. Individual differences in inhibitory control and children's theory of mind. Child Dev 2001;72:1032-53.

37. Chambers C, Cassidy KL, McGrath PJ, Gilbert CA, Craig KD. Child Facial Coding System: A Manual. Dalhousie University and University of British Columbia, 1996.

38. Prkachin KM. The consistency of facial expressions of pain: A comparison across modalities. Pain 1992;51:297-306.

39. Ekman P, Friesen WV. Investigators' guide to the Facial Action Coding System. California: Consulting Psychologists Press, 1978

40. Bieri K, Reeve RA, Champion GD, Addicoat L. The Faces Pain Scale for the self-assessment of the severity of pain experienced by children: Development, initial validation, and preliminary investigation for ratio scale properties. Pain 1990;41:139-50.

41. Dunn LM, Dunn LM. Examiner's manual for the Peabody Picture Vocabulary Test, $3^{\text {rd }}$ edn. Minnesota: American Guidance Service, 1997.

42. Denham SA. Social cognition, prosocial behavior, and emotion in preschoolers: Contextual validation. Child Dev 1986;57:194-201.

43. Markham R, Adams K. The effect of type of task on children's identification of facial expressions. J Nonverbal Beh 1992;16:21-39.

44. Symons D, McLaughlin E, Moore C, Morine S. Integrating relationship constructs and emotional experience into false belief tasks in preschool children. J Exp Child Psychol 1997;67:423-47.

45. Cummings EM, Davies P. Emotional security as a regulatory process in normal development and the development of psychopathology. Dev Psychopathol 1996;8:123-39.

46. Young MR, Fu VR. Influence of play and temperament on the young child's response to pain. Child Health Care 1988;16:209-15.

47. Lee LW, White-Traut RC. The role of temperament in pediatric pain response. Issues Compre Pediatr Nurs 1996;19:49-63.

48. Osborne RB, Hatcher JW, Richtsmeier AJ. The role of social modeling in unexplained pediatric pain. J Pediatr Psychol 1989;14:43-61.

49. Sweet SD, McGrath PJ, Symons D. The roles of child reactivity and parenting context in infant pain response. Pain 1999;80:655-61. 


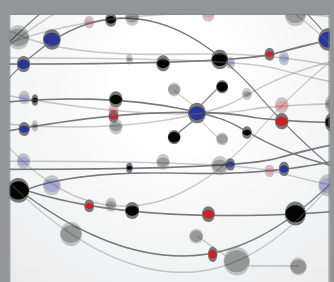

The Scientific World Journal
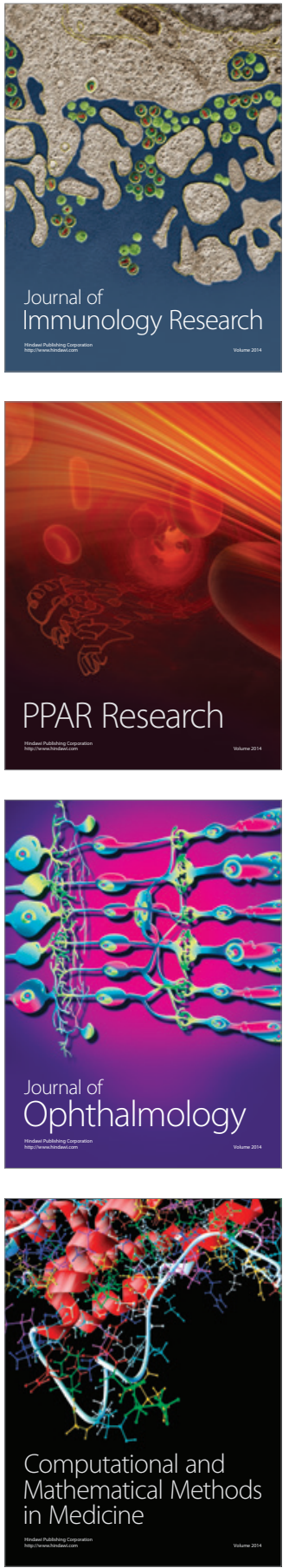

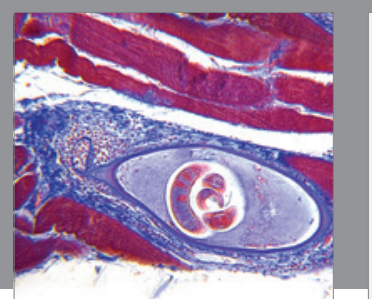

Gastroenterology Research and Practice

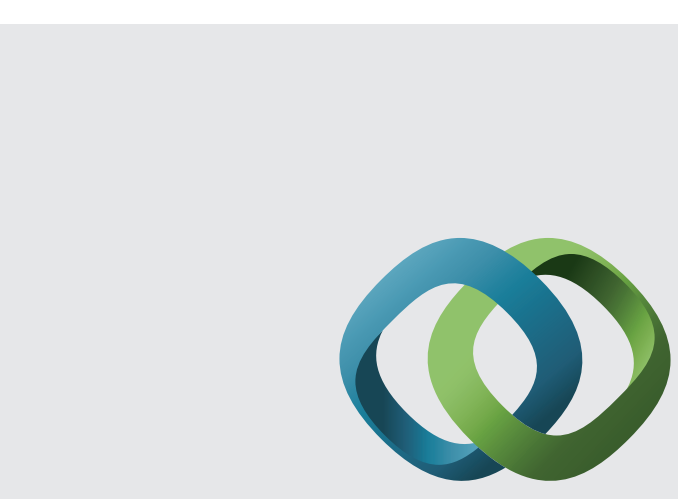

\section{Hindawi}

Submit your manuscripts at

http://www.hindawi.com
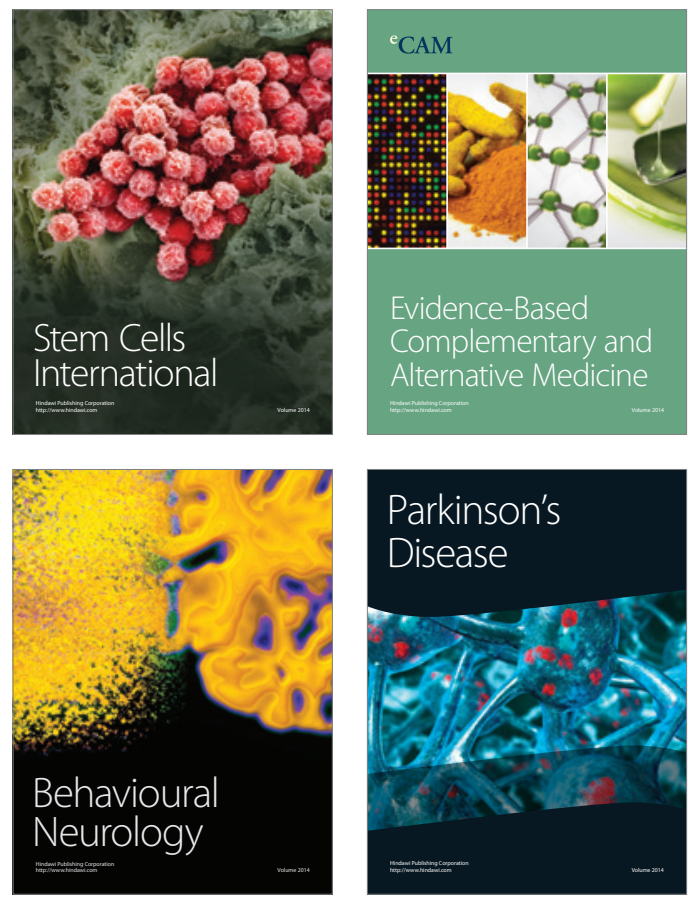
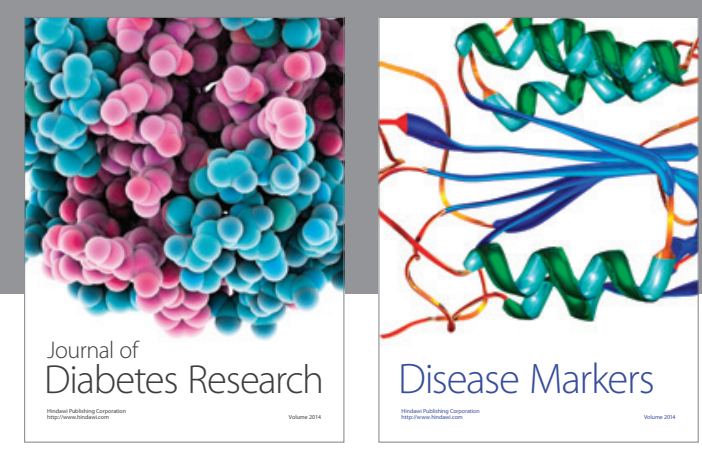

Disease Markers
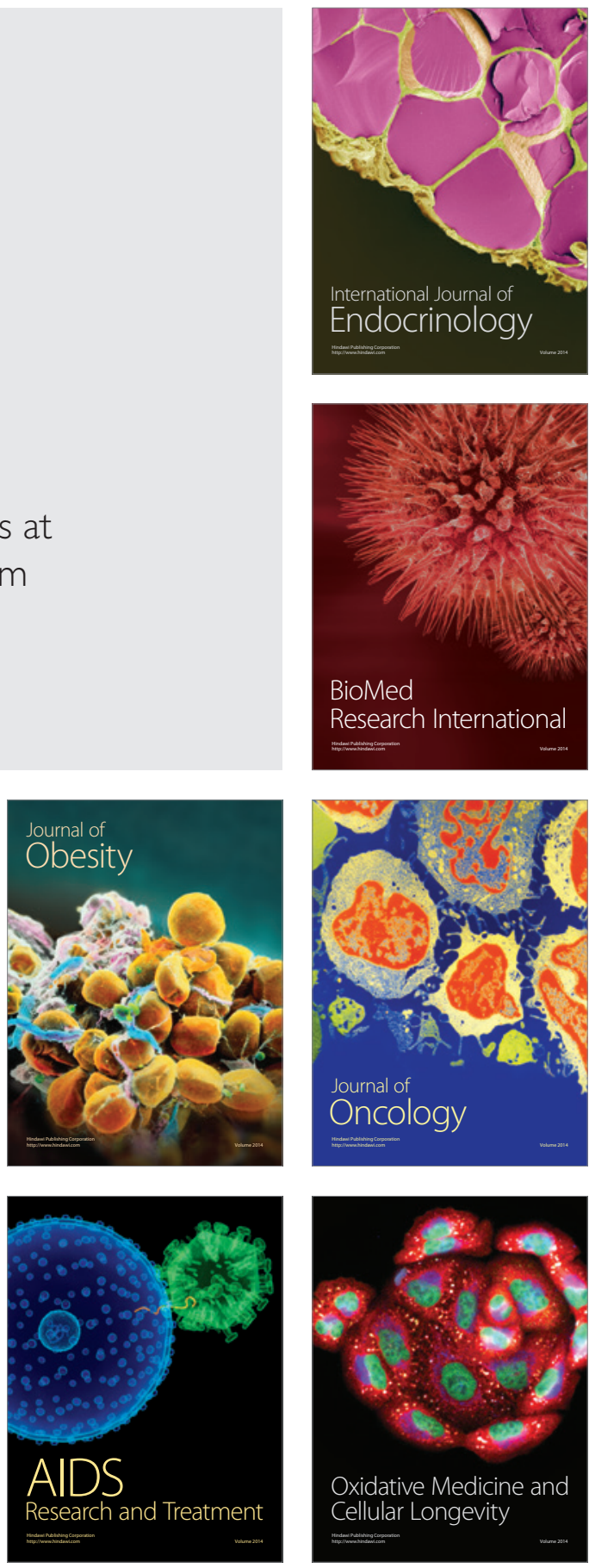